\title{
Role of Rotational Atherectomy in Percutaneous Coronary Interventions in Elderly
}

\section{Introduction}

More than 25 years have passed since the first case of Rotational Atherectomy(RA) was performed by Jerome Ritchie, Davide Auth and colleagues in 1987 [1]. Though coronary angiography and angioplasty has evolved tremendously with introduction of different coronary stents [2,3], balloons and wire, RA continues to have an established role in treatment of complex coronary artery disease in the cardiac cath lab. It was initially introduced as an alternative to balloon angioplasty but has now become an adjunct procedure during coronary intervention, especially of heavily calcified or fibrotic lesions.

RA "debulks" the stenosis by physical removal of plaque, causing plaque modification. This allows delivery of additional devices like stents and balloons, hence increasing procedural success. It is also a useful in treatment of "non dilatable" lesions where balloon angioplasty leads to incomplete lesion dilation prior to stent deployment [4].

Though the procedure is very helpful in treatment of calcified coronary artery disease, the long-term results have not been very encouraging for restenosis and MACE. Initially adopted in upto $10 \%$ of all percutaneous interventions (PCI), nowadays it is used in only $3-5 \%$ of all cases [4].

\section{Procedure Descriptions}

RA is a debulking device that physically removes plaque and reduces plaque rigidity basically altering vessel compliance, similar to that achieved by a dental drill. It works on the principle of "differential cutting", ablating only the calcified and fibrotic "non-compliant" tissue, while retaining the elastic arterial wall. The hard and calcified plaque is not able to deflect the rota-burr and gets ablated producing microfissures at the contact zone. The "ablated" plaque is broken into particles that are smaller than $5 \mathrm{uM}$ in diameter that pass through the vasculature and absorbed by the Reticulo-Endothelial System [4].

The procedure entails a diamond encrusted elliptical burr that is rotated at high speeds (140,000-180,000 rpm) and advanced over a guidewire across the lesion [5]. The guidewire functions to keep the burr coaxial in the lumen of the artery. This is a nickel coated brass burr that is coated with 2000-3000 microscopic diamond particles on the leading edge with a smooth trailing edge. The diamond particles are $20 \mathrm{um}$ in size. The burr comes in various sizes ranging from $1.25 \mathrm{um}$ to $2.5 \mathrm{um}$ and the burr size to be used is determined on the size of the vessel being treated $[6,7]$. It is recommended to keep the burr to artery ration of 0.5-0.6.

The friction between the burr and the plaque produces deceleration and heat that can range from 2.6 C to $13.9 \mathrm{C}$ and varies depending on the decelerations of the burr. Short pecking movements are recommended as excessive decelerations (>

Case Report
Volume 11 Issue 1 - 2018
Sameer Gupta ${ }^{1}$ and Purshotam Lal ${ }^{2 *}$
${ }^{1}$ Consultant, Interventional Cardiology \& Endovascular
Intervention, Metro Hospitals and Heart Institute, India
${ }^{2}$ Director Interventional Cardiology, Metro Hospitals \& Heart
Institute, India
*Corresponding author: Purshotam Lal, Director
Interventional Cardiology, Metro Hospitals \& Heart Institute,
Noida, India, Email: p-lal@ hotmail.com
Received: September 28, 2016 | Published: February 16,
2018

$14,000-18,000)[7,8]$ with increased heat generation and thermal injury can increase the risk of peri-procedural myocardial infarctions and restenosis [7].

The inelastic plaque gets ablated while the healthy arterial wall is unaffected. RA produces a smooth luminal surface and compared to balloon angioplasty and does not produces micro-dissections in the calcified plaques [9-11]. The final lumen diameter is larger that the size of the burr that is used. Most of the particles creating during RA are smaller than $10 \mathrm{um}$ (mean diameter of $5 \mathrm{um}$ ) and easily traverse the microvascularture to be absorebed by the RES [5]. In some cases, the microvasculature can be obstructed causing reduced contractility, slow flow-no reflow and MI. Use of vasodilators, maintenance of arterial blood pressure, using small pecking movements and preventing excessive deccelarations along with use of vasodilators are some of the techniques that can reduce the incidence of slow-flow / no reflow $[12,13]$.

It is important to be cautious and use meticulous technique to prevent the risk of complications associated with use of RA. Some generally accepted best practices include a single burr with a burr to artery ratio of $0.5-0.6$, rotational speed of 140,000 to $150,000 \mathrm{rpm}$, gradual burr advancement, short ablation runs of 15-20 seconds and avoidance of decelerations of more than 5000 rpm.

\section{Indications}

In modern day practices, RA is a tool reserved for severe calcification when there is a increased likelihood of procedural failure, stent underdeployment, and some cases of instent restenosis [4]. It is useful for non-dilatable lesions - when inadequate balloon expansion is noted at the stenosis. In such lesions, RA at such sites prior to stent deployment facilitates stent 
delivery and expansion. An underexpanded stent increases the risk of instent restenosis and thrombosis.

Newer imaging techniques like IVUS (Intravascular ultrasound) and Oct (Optical Coherence Tomography) can precisely determine the location (superficial or deep) and extent of calcification [14]. Angiographically calcification can also be determined with radio-opacifications noted during cine-angiography. Customarily, calcification noted on both sides of the arterial wall without cardiac motion before contrast injection is termed as "severe calcification" $[15,16]$. RA is an essential tool is treatment of such severe calcifications.

It also increases procedural success in other complex lesions like chronic total occlusions, ostial lesions and bifurcation lesions where the plaque morphology along with vessel geometry make the procedure challenging [4].

Syntax score is a angiographic tool used to determine the complexity of coronary artery stenosis [17]. In patients with a high syntax score $(>33)$, cardiac bypass surgery remains the preferred treatment option $[17,18]$. However there remains a group of patients who are not deemed suitable for cardiac bypass surgery secondary to other co-morbidities - severe COPD, repeat CABG, very old age and overall frail status. Medical therapy remains an option for these patients however many such patients cannot tolerate high dose medical therapy secondary to the comorbidities eg: increased wheezing from beta blockers in COPD, hypotension from nitrate and other anginals. We deem these patients as "No Option" patients who are neither candidates for surgery nor respond well to medical therapy. These patients often have severe calcification compounded with a high syntax score that also makes the coronary intervention very high risk.

We present below our personal experience in treating this difficult cohort.

Since 1990, we have experience with multiple debulking devices like extraction coronary atherectomy [19-21], directional coronary atherectomy $[20,21]$ and slow rotational atherectomy [19]. We describe our experience with Rotational Atherectomy from $1^{\text {st }}$ July 2015 to $30^{\text {th }}$ June 2016.

\section{Our Experience}

In the initial days of the introduction of RA, it was used in ostial lesions as well. Those were the days before intracoronary stenting became popular. It was thought that RA would reduce the restenosis by preventing elastic recoil of the artery. One such case was a 48 years old male with RA for ostial lesion in left circumflex artery; this patient happened to be the first case of RA in India in the year 1991; our first clinical experience with RA and other cutting devices was presented in the Annual Conference of Cardiological Society of India in 1992 and 1993 [20-22].

Like other centers, we use RA for heavily calcified lesions where balloon angioplasty/stenting is not possible (primary rotablation), in cases where the conventional method of balloon crossing or dilatation fails (secondary rotablation), for ostial lesions (mostly left main ostial lesions), for in-stent restenosis (for debulking), in cases of unexpanded stent and diffuse coronary artery disease (CAD). Absolute contraindications to RA include saphenous vein graft (SVG) lesion, in-situ thrombus, intimal dissection in or near target lesions and coronary artery occlusion where passage of guide wire is impossible. Relative contraindications to RA include severe left ventricular (LV) dysfunction, lesion length $\geq 25 \mathrm{~mm}$, lesion angulation and non availability of on-site coronary artery bypass graft (CABG) surgery.

From $1^{\text {st }}$ July 2015 to $30^{\text {th }}$ June 2016, a total of 2,256 coronary angioplasties were performed in our center. Rotational atherectomy was done in 181 patients; 82 patients were more than 75 years old age and 24 patients were more than 80 years of age. Out of 82 patients, 59 patients were 'no-option' CAD patients where the patients had undergone one or two bypass graft surgeries and were unfit for another surgery. A number of them had associated comorbidites like chronic obstructive airway disease ('bad lungs'), chronic renal failure. In these patients the balloon angioplasty was not possible and aggressive medical treatment failed to relieve the intractable angina. Common indications of RA were calcified lesions, critical left main disease with bifurcation, diffuse disease and ostial lesions. However, RA was also performed for traditional contraindications to RA such as SVG lesions, acute myocardial infarction (calcified lesions with thrombus) and in-stent restenosis. Complications with RA included slow flow in several patients due to heavily calcified long lesions and were rectified with combination of intra coronary Dilzem and NTG. Burr entrapment happened in one case which was rectified by taking the whole system out which was dealt with covered stent. Non paralytic stroke happened in one patient with spontaneous recovery. All patients had uneventful recovery and were discharged 3-5 days later. On follow-up (ranging from 2-13 months) majority of patients are asymptomatic; however, 3 patients still complain of occasional Class II effort angina. Our experience highlights the fact that 'rota-stenting' is technically useful in difficult-to-treat patients with severe forms of coronary artery disease associated with comorbidities (unpublished data) (Figures 1-4).
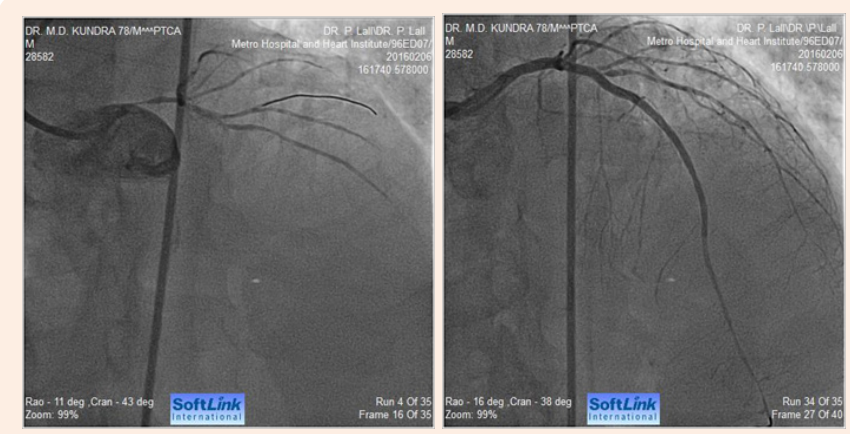

Figure 1: A 78 years old male with Class IV angina and LV ejection fraction of 0.3 . Cranially angulated AP view shows $95 \%$ stenosis of ostial left main coronary artery (LMCA). Fluoroscopy showed extensive calcification involving LMCA, LAD and LCX. Corresponding image on the right side shows fully opened-up LMCA after 'rota-stenting' with a 1.5 $\mathrm{mm}$ burr and deployment of a drug eluting stent from LMCA to LAD. 

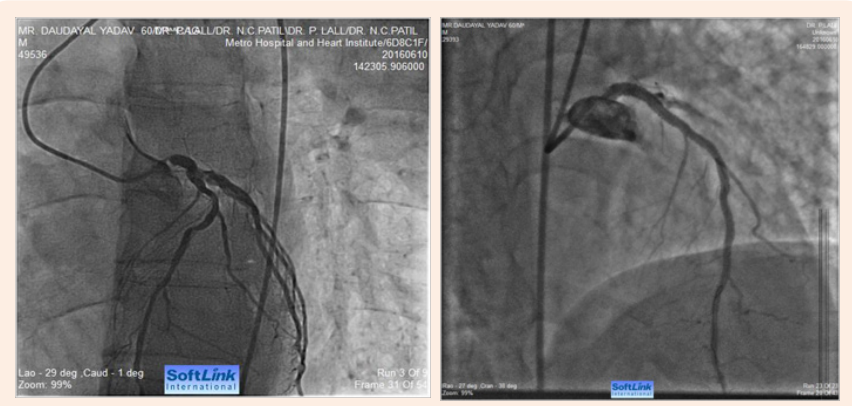

Figure 2: A 60 years old male with recent anterior wall MI and LV ejection fraction of 0.35 with Class III exertional angina. Cranially angulated LAO view shows $95 \%$ stenosis of ostial left main coronary artery (LMCA). The ostial LMCA lesion was pulverized with a $1.5 \mathrm{~mm}$ RA burr (Boston Scientific International S.A., France) over a 0.009" RotaWire (Boston Scientific International S.A., France). Corresponding image on the right side shows fully opened-up LMCA.
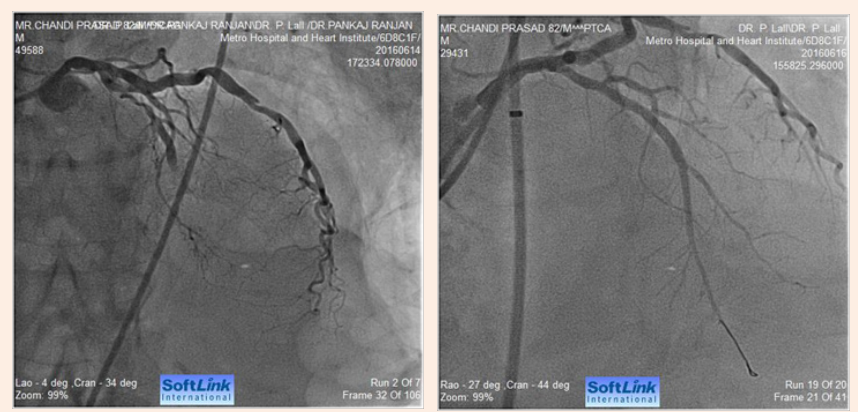

Figure 3: AP-cranial view. An 82 years old male presented with acute anterior wall MI. Coronary angiography revealed total occlusion of mid LAD. Fluoroscopy showed extensive calcification involving LMCA and LAD. The occluded segment was full of thrombus. LAD could not be opened-up despite repeated balloon inflations in progressively increasing sizes. The right panel shows fully opened-up LAD after 'rotastenting' with a $1.25 \mathrm{~mm}$ burr and deployment of a $2.5 \mathrm{~mm}$ drug eluting stent.
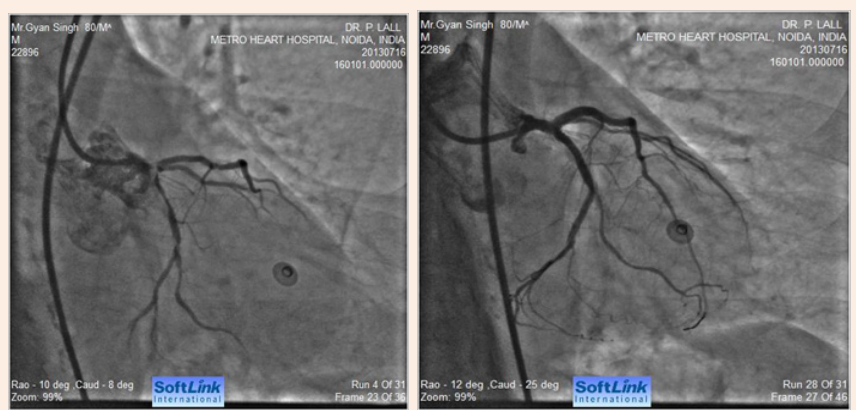

Figure 4: Caudally angulated RAO view of an 80 years old male showing extensive calcification involving distal LMCA extending into ostial LAD and ostial and proximal LCX (bifurcation lesion). The right panel shows fully opened-up LMCA, LAD and LCX after RA with a $1.25 \mathrm{~mm}$ burr and deployment of two drug eluting stents (one from LMCA to LAD and second one in proximal LCX (covering its ostium).

\section{Discussion}

Rotational atherectomy remains an invaluable tool for treating heavily calcified complex coronary arteries disease in the cardiac cath lab. Our experience also shows how it can be a essential tool to treat the "No Option" patients with a high syntax score $(>33)$ who are not candidates for bypass surgery and not responding appropriately to medical therapy. With the aging population and complexity of co-morbidities this population will only increase.

When using rotational atherctomy it is important to size the burr appropriately. In the STRATAS trial, an aggressive burr to artery size ratio (0.7-0.9) was compared to a moderate burr to artery ratio (less than .7). The aggressive group was noted to have a higher restenosis (58\% vs $52 \%$ ) and MI (11\% vs 7\%) [7]. Similar results were also noted in the CARAT trial [6].

According to some studies that have reported follow up for DES after RA, the rates of TLR within $1-2$ yeas are $<10 \%$. In some series, compared to BMS, DES also results in lower MACE rates. This is primarily secondary to lower rates of Target Lesion Revascularization (TLR) [4,23-25].

The ROTAXUS (Rotational Atherectomy Prior to Taxus Stent Treatment for Complex Native Coronary Artery Disease) study compared the effects of RA on moderately to severely calcified vessels prior to DES implantation. There was no difference in MACE in patients who did not undergo RA compared to patients who did receive RA prior to DES implantation [26].

However these studies compared procedural and clinical success in cases with and without RA. In the high risk elderly cohort RA has not been compared to medical therapy. In patients who are at a prohibitive risk for cardiac bypass surgery either because of other co-morbidities, frail status or previous cardiac bypass surgery and not responding to medical therapy, coronary angioplasty and stent implantation remains the only treatment options. Given the increased angiographic complexity often found in this subset of patients, rotational atherectomy remains and important tool and according to our experience can be utilized safely to facilitate the procedure.

It is important to have exhausted medical treatment options so as to justify the intervention. It is also imperative to use meticulous technique to limit the risk of complications.

Rotational atherectomy remains essential tool facilitating procedural success in treatment of calcified complex lesions. In our experience it remains a useful and safe tool in treating the "No Option" patients that have complex coronary artery disease, high syntax score and neither candidates for cardiac bypass surgery nor responding adequately to medical therapy.

\section{References}

1. Ritchie JL, Hansen DD, Intlekofer MJ, Hall M, Auth DC (1987) Rotational approaches to atherectomy and thrombectomy. Z Kardiol Suppl 6: 59-65.

2. Iqbal J, Onuma Y, Ormiston J, Abizaid A, Waksman R, et al. (2014) Bioresorbable scaffolds: rationale, current status, challenges, and future. Eur Heart J 35(12): 765-776.

3. Iqbal J, Gunn J, Serruys PW (2013) Coronary stents: historical development, current status and future directions. Br Med Bull 106: 193-211.

4. Tomey MI, Kini AS, Sharma SK (2014) Current Status of Rotational Atherectomy. JACC Cardiovasc Interv7(4): 345-353. 
5. Hansen DD, Auth DC, Vracko R, Ritchie JL (1988) Rotational atherectomy in atherosclerotic rabbit iliac arteries. Am Heart J 115(1 Pt 1): 160-165.

6. Safian RD, Feldman T, Muller DW, Mason D, Schreiber T, et al. (2001) Coronary angioplasty and Rotablator atherectomy trial (CARAT): immediate and late results of a prospective multicenter randomized trial. Catheter Cardiovasc Interv 53(2): 213-220.

7. Whitlow PL, Bass TA, Kipperman RM, Sharaf BL, Ho KK, et al. (2001) Results of the study to determine rotablator and transluminal angioplasty strategy (STRATAS). Am J Cardiol 87(6): 699-705.

8. Reisman M, Shuman BJ, Harms V (1998) Analysis of heat generation during rotational atherectomy using different operational techniques. Cathet Cardiovasc Diagn 44(4): 453-455.

9. Farb A, Roberts DK, Pichard AD, Kent KM, Virmani R, et al. (1995) Coronary artery morphologic features after coronary rotational atherectomy: insights into mechanisms of lumen enlargement and embolization. Am Heart J 129(6): 1058-1067.

10. Mintz G S, Potkin B N, Keren G, Satler L F, Pichard A D, et al. (1992) Intravascular ultrasound evaluation of the effect of rotational atherectomy in obstructive atherosclerotic coronary artery disease. Circulation 86(5): 1383-1393.

11. Jiménez-Valero S, Galeote G, Sánchez-Recalde A, Moreno R (2009) Optical coherence tomography after rotational atherectomy. Rev Esp Cardiol 62(5): 585-586.

12. Hanna GP, Yhip P, Fujise K, Schroth GW, Rosales OR, et al. (1999) Intracoronary adenosine administered during rotational atherectomy of complex lesions in native coronary arteries reduces the incidence of no-reflow phenomenon. Catheter Cardiovasc Interv 48(3): 275-278.

13. Matsuo $\mathrm{H}$, Watanabe $\mathrm{S}$, Watanabe $\mathrm{T}$, Warita $\mathrm{S}$, Kojima $\mathrm{T}$, et al. (2007) Prevention of no-reflow/slow-flow phenomenon during rotational atherectomy--a prospective randomized study comparing intracoronary continuous infusion of verapamil and nicorandil. Am Heart J 154(5): 994.

14. Mintz GS, Popma JJ, Pichard AD, Kent KM, Satler LF, et al. (1995) Patterns of calcification in coronary artery disease. A statistical analysis of intravascular ultrasound and coronary angiography in 1155 lesions. Circulation 91(7): 1959-1965.

15. Reifart N, Vandormael M, Krajcar M, Göhring S, Preusler W, et al. (1997) Randomized comparison of angioplasty of complex coronary lesions at a single center. Excimer Laser, Rotational Atherectomy, and Balloon Angioplasty Comparison (ERBAC) Study. Circulation 96(1) 91-98.
16. Levin TN, Holloway S, Feldman T (1998) Acute and late clinical outcome after rotational atherectomy for complex coronary disease. Cathet Cardiovasc Diagn 45(2): 122-130.

17. Girasis C, Garg S, Räber L, Sarno G, Morel MA, et al. (2011) SYNTAX score and Clinical SYNTAX score as predictors of very long-term clinical outcomes in patients undergoing percutaneous coronary interventions: a substudy of SIRolimus-eluting stent compared with pacliTAXel-eluting stent for coronary revascularization (SIRTAX) trial. Eur Heart J 32(24): 3115-3127.

18. Mohr FW, Morice MC, Kappetein AP, Feldman TE, Ståhle E, et al. (2013) Coronary artery bypass graft surgery versus percutaneous coronary intervention in patients with three-vessel disease and left main coronary disease: 5-year follow-up of the randomised, clinical SYNTAX trial. The Lancet 381(9867): 629-638.

19. (1991) Slow Rotational Angioplasty - Application in Chronic Total Occlusion Indian Heart Journal 43(4).

20. (1991) Coronary Atherectomy - a new approach for treatment of obstructive coronary artery disease. Indian Heart Journal 43(4).

21. (1992) Directional, Rotational and Extraction Coronary Atherectomy - Initial Experience. Indian Heart Journal 1992(14(A)).

22. (1993) Outcome of osital lesion treated with high speed rotational ablation (Rotablator). Indian Heart Journal 191(358).

23. Mangiacapra F, Heyndrickx GR, Puymirat E, Peace AJ, Wijns W, et al. (2012) Comparison of drug-eluting versus bare-metal stents after rotational atherectomy for the treatment of calcified coronary lesions. Int J Cardiol 154(3): 373-376.

24. Fujimoto, H., et al., Usefulness of rotational atherectomy for the implantation of drug-eluting stents in the calcified lesions of hemodialysis patients. J Cardiol, 2010. 55(2): p. 232-7.

25. Tamekiyo, H., et al., Clinical outcomes of sirolimus-eluting stenting after rotational atherectomy. Circ J, 2009. 73(11): p. 2042-9.

26. Abdel-Wahab, M., et al., High-speed rotational atherectomy before paclitaxel-eluting stent implantation in complex calcified coronary lesions: the randomized ROTAXUS (Rotational Atherectomy Prior to Taxus Stent Treatment for Complex Native Coronary Artery Disease) trial. JACC Cardiovasc Interv, 2013. 6(1): p. 10-9. 